\title{
Impact of Different Reperfusion Modalities on Ventricular Function After Acute Myocardial Infarction
}

\author{
WILLIAM W. O'NEILL, MD
}

Single-plane contrast ventriculography was performed on admission and before hospital discharge in more than 200 patients with acute myocardial infarction participating in a series of prospective clinical trials including intracoronary streptokinase, percutaneous transluminal coronary angioplasty (PTCA), intravenous tissue plasminogen activator (rt-PA) and thrombolysis (intravenous rt-PA or streptokinase) followed by PTCA. Both global ejection fraction (EF) and regional wall motion of the infarct zone were measured to assess serial changes. Patients treated with intracoronary streptokinase 3.6 \pm 1.8 hours after symptom onset had no increase in EF (mean change $1 \pm 6 \%$, difference not significant [NS]), but patients treated with primary PTCA at $3.0 \pm 1.2$ hours did (mean improvement $8 \pm$ $7 \%, p<0.001$ ). Patients treated with sequential intravenous streptokinase and PTCA $2.6 \pm 1.3$ hours after symptom onset showed similar improvement in EF (mean change $6 \pm 12 \%, p<0.002$ ). Patients treated with rt-PA had no change in EF whether treated with rt-PA alone or rt-PA followed by imme- diate angioplasty (mean change $-2 \pm 8 \%$ and 0.5 $\pm 8 \%, p=N S$, respectively). When angioplasty was used in patients with persistent occlusion after thrombolytic therapy, EF improved in those who had received intravenous streptokinase (mean change $10 \pm 7 \%, p<0.002)$, but not those who had received rt-PA $(+0.5 \%, p=N S)$. However, infarct zone regional wall motion improved in patients treated with intracoronary streptokinase $(+0.59 \pm$ 0.79 standard deviation/chord, $p<0.05$ ), primary PTCA (+1.32 $\pm 1.32, p<0.001)$, intravenous streptokinase and PTCA (+1.2 \pm 1.2 standard deviation/chord, $p<0.003$ ), intravenous $t-P A$ alone $(+0.43 \pm 1.0, p=0.002)$ or intravenous $r t-P A$ and immediate PTCA $(+0.37 \pm 1.0, p=0.0001)$. Whereas serial improvement in EF appears to be limited to patients treated with primary PTCA or PTCA after intravenous streptokinase therapy, infarct zone regional wall motion improved regardless of the reperfusion method used.

(Am J Cardiol 1988;61:45G-53G) $\mathrm{n}$ the 1980 s, the therapy of acute myocardial infarction has increasingly involved attempts to reperfuse the infarct zone, given the mounting evidence that timely reperfusion results in a lower mortality than conventional care ${ }^{1,2}$ Although reperfusion itself may improve survival, ${ }^{3}$ the primary mechanism of decreasing mortality is presumed to be a reduction in infarct size. ${ }^{4}$ Reperfusion strategies have included various intracoronary ${ }^{5}$ and intravenous ${ }^{1}$ thrombolytic therapies, percutaneous transluminal coronary angioplasty (PTCA) ${ }^{6}$ coronary bypass ${ }^{7}$ and the combination of thrombolytic therapy and PTCA. ${ }^{8}$

From the Division of Cardiovascular Diseases, Department of Internal Medicine, William Beaumont Hospital, Royal Oak, Michigan; and the Division of Cardiology. Department of Internal Medicine, University of Michigan, Ann Arbor, Michigan.

Address for reprints: William W. O'Neill, MD, Division of Cardiovascular Disease. William Beaumont Hospital, 3601 W. Thirteen Mile Road, Royal Oak, Michigan 48072.
The comparative efficacy of these strategies has been evaluated based on 3 primary endpoints: (1) coronary recanalization rates, (2) mortality reduction, and (3) limitation of infarction size. Whereas recanalization rates and mortality are easily evaluated, clinical quantification of infarct size has been difficult, relying on changes in systolic ventricular function with reperfusion. Although both contrast and radionuclide ventriculographic determination of global ejection fraction (EF) and regional wall motion have severe limitations in quantification of infarction size, ${ }^{9}$ they have gained widespread acceptance because of the ability to standardize values and to perform these studies in a sequential fashion in most patients. More important to their acceptance, however, is the fact that global ventricular function after reperfusion has important prognostic value. ${ }^{3,10}$

Since the inception of the coronary intervention program at the University of Michigan in 1981, we have attempted to systematically assess the impact of 
different reperfusion modalities on changes in ventricular function after reperfusion therapy. The comparative recanalization rates of these treatment methods have been reported previously. ${ }^{11}$ This study will deal with the associated changes in ventricular function.

\section{Methods}

Patients: Study 1: Between March 1981 and June 1982,76 patients with suspected acute myocardial infarction were recruited for a randomized placebo-controlled clinical trial of intracoronary streptokinase administration. ${ }^{12}$ Inclusion criteria included admission to the hospital within 6 hours of symptom onset, $\geq 2 \mathrm{~mm}$ of ST-segment elevation in 2 or more involved electrocardiographic leads and absence of cardiogenic shock. Patients who had a contraindication to thrombolytic therapy or who were unable to give informed consent were excluded. Immediate cardiac catheterization was performed using either the Judkins or Sones technique. Left ventricular end-diastolic pressure was measured and contrast ventriculography was performed in the $30^{\circ}$ right anterior oblique projection. After ventriculography, selective coronary angiography was performed in multiple projections. If complete coronary occlusion was present and unresponsive to intracoronary nitroglycerin, and if narrowing of the left main coronary artery greater than $70 \%$ was absent, patients were then randomized to receive either intracoronary streptokinase (total dose of 250,000 IU) or a dextrose solution. At the termination of infusion, arterial patency status was assessed and contrast ventriculography was repeated. A radionuclide ventriculogram was obtained within 72 hours (mean \pm standard deviation [SD] $42 \pm 27$ hours), at $12 \pm 4$ days after admission and $5 \pm 3$ months after discharge. Analysis of left ventricular wall motion by contrast angiography was performed with standard catheterization laboratory computer and software (Electronics for Medicine, Honeywell). End-diastolic and end-systolic contours were traced and digitized with the computer light pen system, using only sinus beats not preceded by a premature beat. EF was calculated using the area-length method.

Study II: Between April 1, 1984 and October 31, 1984, 72 patients were enrolled in a 2-center randomized clinical trial of intracoronary streptokinase vs coronary angioplasty therapy, conducted at the University of Michigan Medical Center and William Beaumont Hospital, Royal Oak, Michigan. ${ }^{13}$ Inclusion criteria were as previously described, with the additional requirement that patients not have left main coronary stenosis of $>60 \%$, "left main coronary artery equivalent" disease, ( $>70 \%$ stenosis of both proximal left anterior descending and proximal circumflex vessels), occlusion of a saphenous vein graft, or a distal occlusion of a tortuous circumflex artery judged not suitable for angioplasty. Fifty-six patients $(78 \%)$ met these inclusion criteria, and were randomized to either immediate coronary angioplasty (29 patients) or intracoronary streptokinase infusion ( 27 patients). All patients received 5,000 $\mathrm{U}$ of heparin, and those patients under- going angioplasty received an additional 5,000 $\mathrm{U}$ after randomization. They were maintained on an infusion of low molecular weight dextran $(40 \mathrm{ml} / \mathrm{min}$ for 24 hours), and received aspirin (325 $\mathrm{mg}$ ) and oral nifedipine ( 20 to $30 \mathrm{mg}$ every 8 hours) in addition to a 24 -hour infusion of nitroglycerin. Patients undergoing angioplasty also received verapamil ( $5 \mathrm{mg}$ intravenously) before the procedure and intracoronary nitroglycerin $(200 \mu \mathrm{g})$ immediately before angioplasty. Changes in ventricular function were assessed based on admission and predischarge contrast left ventriculograms recorded in 46 of the 56 patients, and analyzed using the area-length method and the computer-assisted centerline chord method. ${ }^{14}$

Study III: Between November 1, 1984 and September $21,1985,34$ consecutive patients were treated with sequential high-dose intravenous streptokinase 11.5 million units) and emergency coronary angioplasty in a prospective nonrandomized clinical study. ${ }^{8}$ Clinical inclusion criteria were the same as the 2 previous randomized investigations. Heparin therapy consisted of $5,000 \mathrm{U}$ administered intravenously at the start of catheterization, an additional 5,000 U administered before angioplasty, and a continuous infusion initiated when serum fibrinogen level was $\geq 100 \mathrm{mg} / \mathrm{dl}$ maintained until predischarge angiography 7 to 10 days later.

Study IV: Between September 21, 1985 and January 31,1986 , a pilot, randomized, prospective clinical trial of immediate vs delayed coronary angioplasty was conducted after successful thrombolytic therapy using recombinant tissue-type plasminogen activator (rt$\mathrm{PA})^{14}$ as part of a 4 -center trial of rt-PA sponsored by Genetech Inc. (South San Francisco, California). ${ }^{15} \mathrm{~Pa}$ tients were treated with an intravenous infusion of rtPA at a dose of $1.25 \mathrm{mg} / \mathrm{kg}$ administered over 3 hours. At the University of Michigan, 50 patients were recruited, including 38 randomized to rt-PA infusion and 12 to placebo. The 38 patients treated with rt-PA underwent coronary angiography 2 hours after onset of infusion, which demonstrated an $84 \%$ patency rate of the infarct-related artery. Twenty-eight of these patients met predefined angiographic criteria and underwent a second randomization to either immediate or deferred PTCA. Contrast left ventricular angiography in the right anterior oblique projection was performed at the time of initial catheterization (before PTCA) and at the time of hospital discharge 7 to 10 days later, and were analyzed as previously described.

Most recently, we have tested the feasibility of a regionalized approach to interventional therapy of acute myocardial infarction. ${ }^{16}$ Patients who presented to W.A. Foote Memorial Hospital, Jackson, Michigan and South Macomb Hospital, Warren, Michigan, had rt-PA infusion initiated at the community hospital and were then immediately transported to the University of Michigan Medical Center for cardiac catheterization and coronary intervention. Topol et al. ${ }^{16} \mathrm{com}$ pared the reperfusion rates and changes in global and regional ventricular function in these patients to patients in whom rt-PA infusion was initiated on arrival at the University of Michigan, or patients in whom rtPA was flown to the local community hospital and 
infusion was initiated during helicopter transport. Catheterization procedures, coronary angiography, contrast ventriculography and pharmacologic therapy were the same as the previous rt-PA protocols.

\section{Results}

Intracoronary streptokinase therapy: The results of the initial randomized, placebo-controlled study of intracoronary streptokinase infusion have been reported by Khaja et al. ${ }^{12}$ Intracoronary streptokinase infusion $(n=20)$ or dextrose solution $(n=20)$ were administered $5.4 \pm 1.9$ hours after symptom onset, with coronary recanalization in $60 \%$ of streptokinasetreated patients. Contrast ventriculograms showed no change in either global EF or infarct zone regional wall motion. Only 3 of 19 patients treated with streptokinase and 3 of 20 treated with placebo had a global EF improvement of 5 percentage points or more (Fig. 1). To evaluate any later improvement in EF, radionuclide ventriculography was performed within 72 hours, at the time of hospital discharge and 3 months after discharge. Again, no differences were seen in the EF of the streptokinase-treated group compared with the placebo-treated control group (Fig. 2). Centerlinechord methodology for analysis of regional wall motion was not available at this time.

The next randomized clinical tria $\mathrm{l}^{13}$ compared intracoronary streptokinase infusion to primary PTCA therapy. Twenty-three of 27 patients $(85 \%)$ achieved anterograde recanalization with streptokinase at $4.8 \pm$ 1.7 hours of symptom onset. EF was unchanged (48\% initial, $49 \%$ predischarge), but infarct zone regional wall motion improved significantly (increased regional wall motion of $0.59 \pm 0.79 \mathrm{SD} /$ chord, $\mathrm{p}=0.05$ ).

Percutaneous transluminal coronary angioplasty: Twenty-nine other patients were randomized to primary PTCA in the aforementioned trial, ${ }^{13}$ with coronary recanalization in 24 of 29 patients (83\%) at $4.1 \pm$ 1.4 hours from symptom onset. Nineteen of these patients had adequate quality serial contrast ventriculograms on admission and hospital discharge, with an increase in global $\mathrm{EF}$ from 48 to $56 \%$ (mean improvement $8 \pm 7 \%, \mathrm{p}<0.001$ ). When the serial changes in contrast EF were compared for the streptokinase- and angioplasty-treated groups (Fig. 3), 14 of 19 patients treated with angioplasty but only 4 of 20 patients treated with streptokinase had a $\geq 5 \%$ increase in $E F$. Greater improvement in infarct zone regional wall motion (1.32 $\pm 1.32 \mathrm{SD} /$ chord) was also evident in the PTCA-treated group compared with the streptokinase-treated group $(\mathrm{p}<0.001)$.

\section{CHANEES IN GLOBAL EJECTION FRACTION HFH-UMMC RANDOM TRLAL}

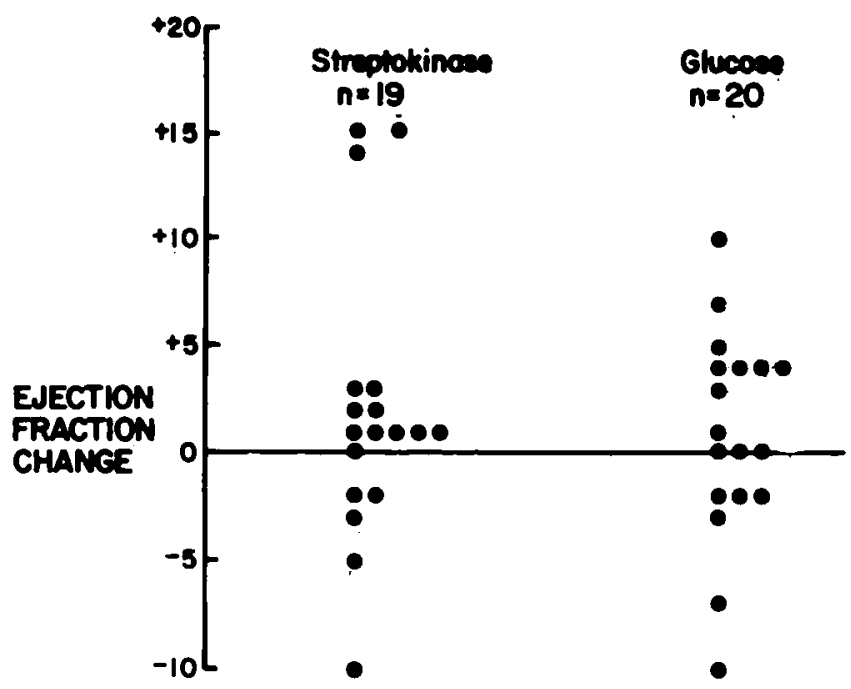

FIGURE 1. Changes in serial contrast ventriculographic ejection fraction before and after therapy. Streptokinase-treated patients received therapy 5.3 hours after symptom onset. Only 3 patients in each subgroup had global ejection fraction increase by at least 5 percentage points. Four patients did not have paired contrast studles. HFH-UMMC $=$ Henry Ford Hospital-Universily of Michigan Medical Center.
FIGURE 2. Global ejection fraction as measured from radionuclide ventriculograms. Studies were obtained early (42 \pm 26 hours), intermediate ( $12 \pm 4$ days) and late (52 \pm 3 months). Differences in mean values (bars) were not statistically different between time periods. Squares connected by broken lines are reperfused palients; circles, the nonreperfused group.

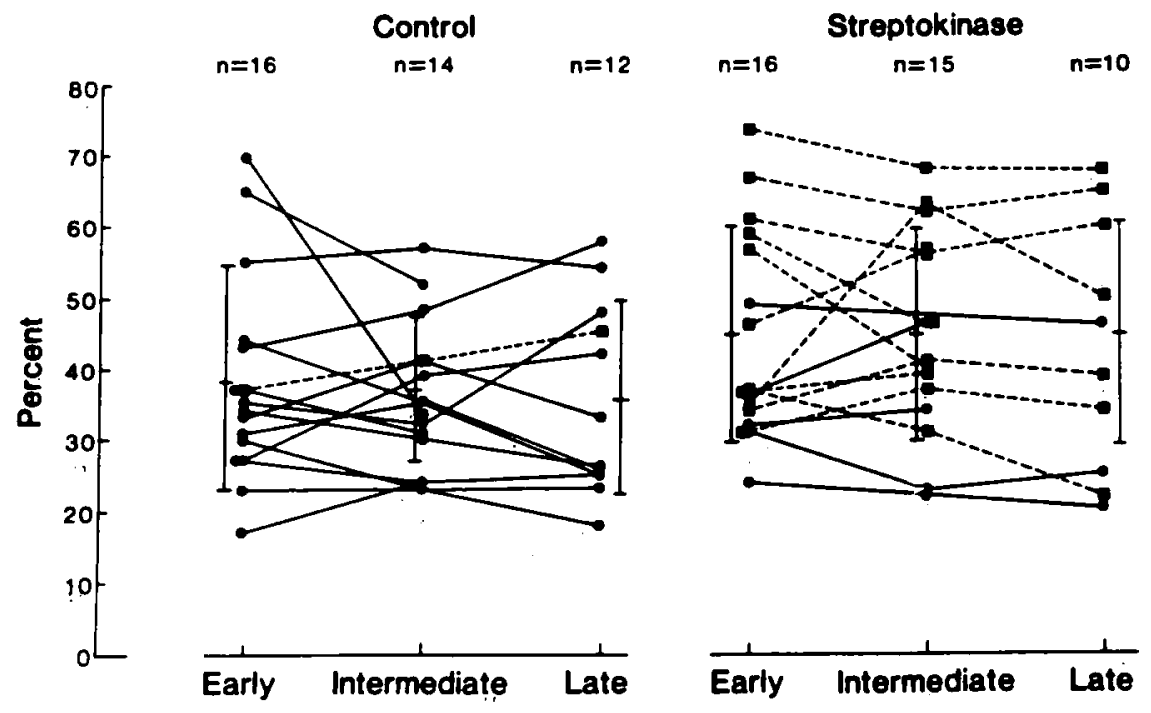


Sequential intravenous streptokinase and percutaneous transluminal coronary angioplasty: Fung et al. ${ }^{8}$ reported on 34 patients treated with 1.5 million units of intravenous streptokinase followed by immediate catheterization and PTCA. When streptokinase infusion was initiated 2.6 hours after symptom onset, angiography documented a coronary patency rate of $62 \%$. Coronary angioplasty was performed in 29 of 34

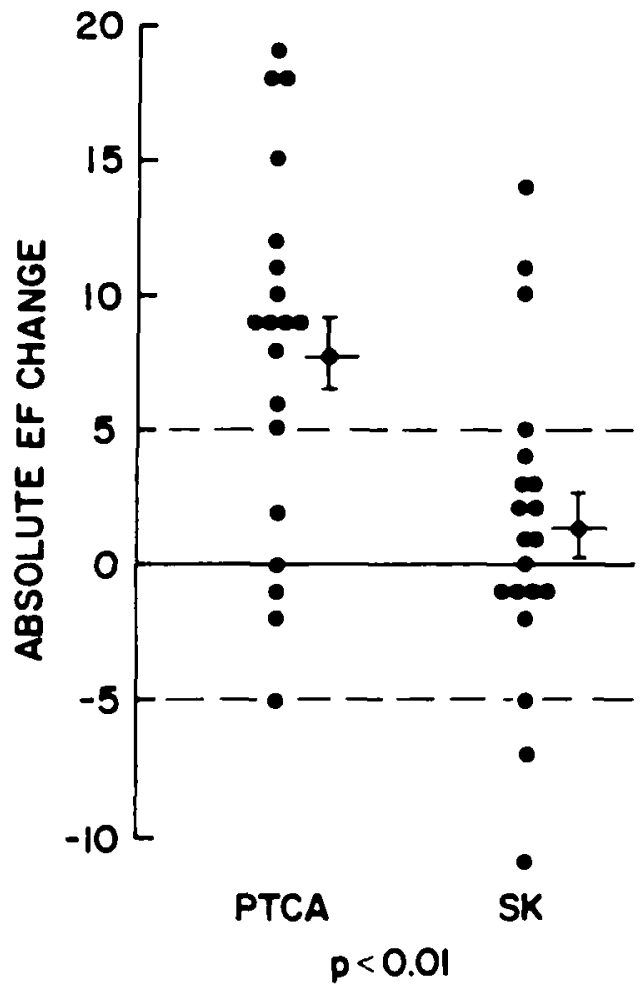

FIGURE 3. Changes in serial ejection fraction were determined from analyses of serial contrast ventriculograms obtained before therapy and before hospital discharge. The mean \pm standard error of the mean are shown. SK = streptokinase; PTCA = percutaneous transluminal coronary angioplasty. patients. Of the remaining 5 patients who did not have PTCA, the residual stenosis in the infarct-related artery was $\leq 50 \%$ at the time of immediate catheterization in 3 , and lesions were located in the distal segments of small infarct-related arteries that were not judged suitable for PTCA in 2 patients, respectively. PTCA was successful in all 16 patients with subtotal coronary occlusion, and in 12 of 13 patients with persistent total occlusion despite thrombolytic therapy. Global EF improved from an initial EF of $53 \pm 12 \%$ to $59 \pm 13 \%(\mathrm{p}<0.002)$ at the time of hospital discharge (mean increase $6 \pm 12 \%$ ). Additionally, regional wall motion of the infarct segment improved from $-2.7 \pm$ 1.1 to $-1.5 \pm 1.7 \mathrm{SD} /$ chord ( $\mathrm{p}<0.003$ ) (mean change $+1.2 \pm 1.2 \mathrm{SD} / \mathrm{chord}$ ). When patients were subgrouped based on successful thrombolysis or unsuccessful thrombolysis, important differences in a change in ventricular function occurred (Fig. 4). $\mathrm{Pa}$ tients with successful thrombolysis tended to have a higher initial EF ( $56 \pm 10 \%$ vs $49 \pm 12 \%, \mathrm{p}=0.18$ ), and more effectively preserved regional wall motion $[-2.2$ \pm 1.0 vs $-3.2 \pm 1.0 \mathrm{SD} /$ chord, $\mathrm{p}<0.03$ ) than patients with continued occlusion. No significant further improvement occurred in the patients who had successful thrombolytic therapy, with an EF of $58 \pm 10 \%$ initially and $59 \pm 10 \%$ at the time of hospital discharge $(p=0.19)$. However, there was a trend toward improvement in regional function of the infarct zone: $-2.2 \pm 1.0$ to $-1.2 \pm 1.8 \mathrm{SD} /$ chord $(\mathrm{p}=0.06)$. In patients with continued occlusion after thrombolytic therapy, both global EF $(49 \pm 12 \%$ to $59 \pm 12 \%, \mathrm{p}<0.002)$ and regional wall motion $(-3.2 \pm 1$ to $-1.9 \pm 1.7 \mathrm{SD} / \mathrm{chord}$, $\mathrm{p}<0.002$ ) increased significantly by the time of hospital discharge.

Tissue plasminogen activator therapy: Coronary recanalization was documented angiographically in 32 of 38 patients $(84 \%)$ treated with rt-PA $(1.25 \mathrm{mg} / \mathrm{kg})$ over 3 hours. Thirteen patients were randomized to rtPA infusion alone, initiated $4.1 \pm 1.1$ hours after symptom onset with estimated reperfusion at $5.4 \pm 1.4$ hours. The EF in this group was $52 \pm 12 \%$ initially and

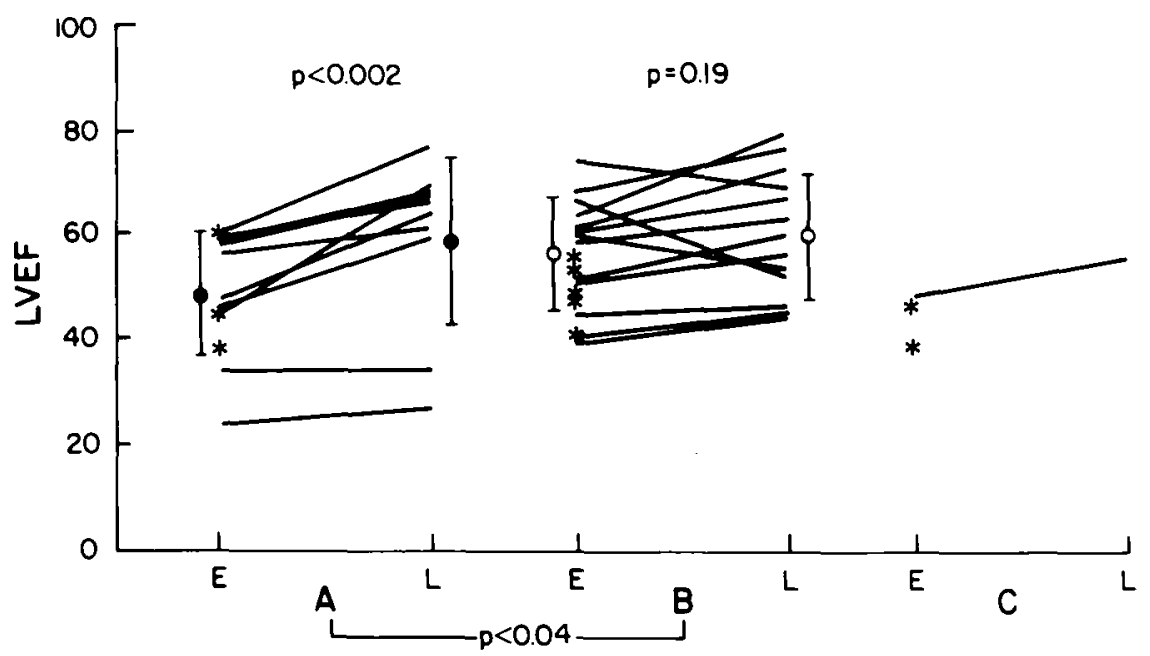

FIGURE 4. Left ventricular ejection fraction (LVEF) on initial angiography early ( $E$ ) and 10 days after therapy, $A$, patients with initially unsuccessful thrombolytic therapy; $B$, patients with initial successful thrombolytic therapy; $C$, patients with widely patent infarct-related arteries at the time of initial catheterization. $L=$ late. 
FIGURE 5. Infarct zone regional wall motion changes and global left ventricular ejeclion fraction (EF) changes for patients treated with intravenous tissue plasminogen activator ( $t-P A)$ alone or $t-P A$ and angloplasty. No change in global ejection fraction occurred for the groups whether t-PA alone or t-PA + percutaneous transluminal coronary angioplasty (PTCA) was applied. Infarct zone regional wall molion was significantly Improved for patients treated by $\mathrm{t}$-PA and PTCA. NS = not significant; $S D=$ standard deviation.
Intarct Regional Wall Motion

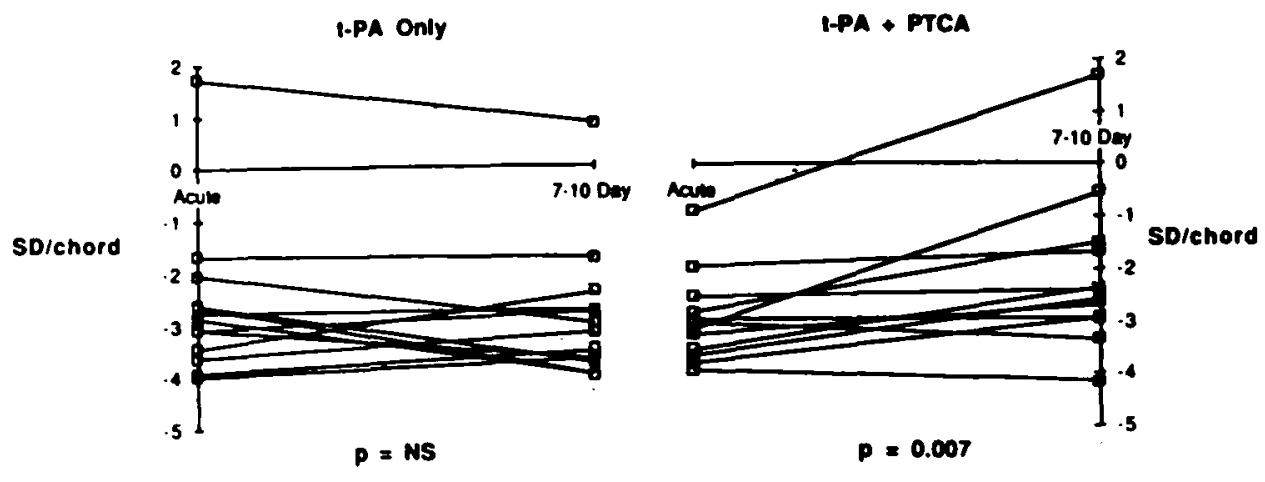

Left Ventricular Global Function

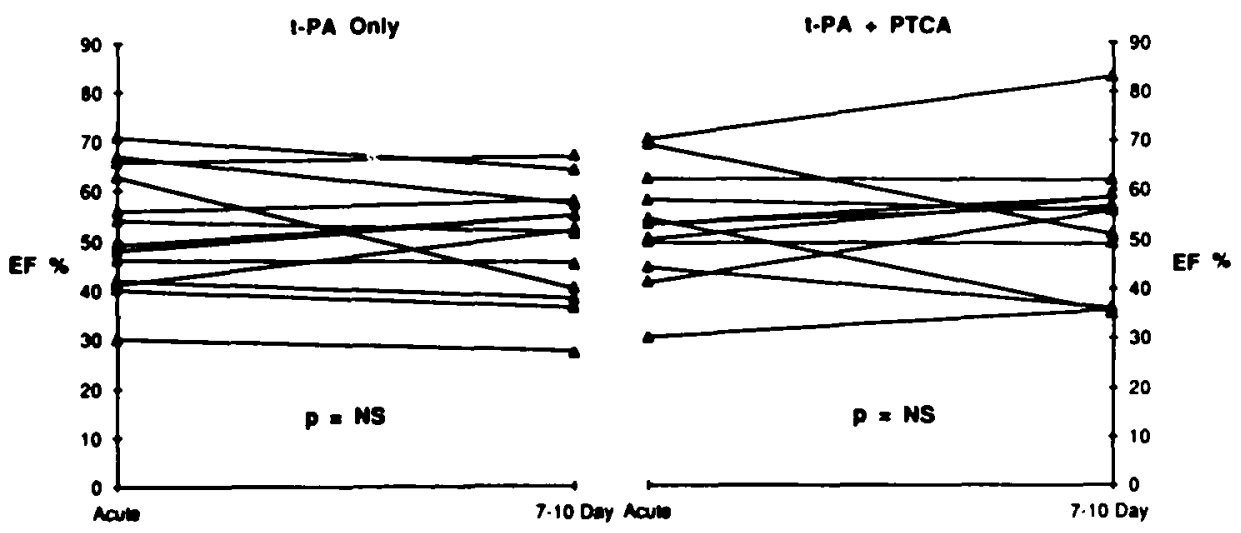

$50 \pm 11 \%$ at discharge (mean change $-2.11 \pm 8 \%$, difference not significant [NS]). Regional wall motion was $-2.62 \pm 1.41 \mathrm{SD} /$ chord initially and $-2.86 \pm 1.23$ $\mathrm{SD} / \mathrm{chord}(\mathrm{p}=\mathrm{NS})$. Fifteen patients were treated with immediate angioplasty after successful rt-PA infusion. In these patients, global EF was $53 \pm 11 \%$ at entry and $53 \pm 13 \%$ at discharge ( $p=N S$ ), but regional wall motion improved significantly from $-2.94 \pm 0.82$ to $-2.11 \pm 1.45 \mathrm{SD} /$ chord (mean change $0.83 \pm 0.094, \mathrm{p}$ $<0.007)$. Two of 15 patients treated with rt-PA and PTCA vs 2 of 13 patients treated by rt-PA alone had a $\geq 5 \%$ increase in global EF (Fig. 5).

Community hospital administration of intravenous tissue plasminogen activator: To further decrease the interval from symptom onset to thrombolytic therapy, we attempted to institute a program permitting administration of rt-PA in community hospitals rather than having patients flown by helicopter to our referral center before initiation of therapy. ${ }^{16}$ Using this strategy, the duration of symptoms before drug administration could be decreased, from $3.8 \pm 1.2$ to $2.1 \pm 0.8$ hours. Early drug administration appeared to yield more effective preservation of ventricular function, since patients treated at the community hospital had an initial EF of $54 \pm 8 \%$ compared with $50 \pm 9 \%$ (p
$<0.01$ ) in patients in whom therapy was initiated at our referral center. This preservation of ventricular function tended to persist until hospital discharge, with patients treated in the community hospital having an EF of $55 \pm 9 \%$ compared with $52 \pm 10 \%(p=0.08)$ for those treated at the referral center.

\section{Discussion}

Preservation of ventricular function after reperfusion plays a dominant role in determining survival after hospital discharge. Our serial experience using different reperfusion strategies and agents has provided data regarding the effect of these treatment modalities on left ventricular function. Single-plane, right anterior oblique contrast ventriculography was performed at initial catheterization and (except for Study 1) at the time of hospital discharge, allowing nonrandomized comparison among groups. Because these studies involve small numbers of patients treated with different initial success rates, subsequent reocclusion rates and adjunctive therapies, such comparisons must be made cautiously.

Our 2 randomized trials of intracoronary streptokinase administration demonstrated no improvement in global ventricular function. Analysis of 7 randomized 
trials published to date (Fig. 6) reveals that efficacy is time-dependent, with significant improvement in EF confined to the studies of Anderson et al ${ }^{17}$ and Simoons et al, ${ }^{2}$ in which the time to initiation of streptokinase therapy was shortest. Because intracoronary streptokinase infusion imposes an obligatory time delay of 1 to 2 hours from presentation to the initiation of drug therapy, it is unlikely that most patients could be treated within this 4-hour time window. Lack of improvement in global EF, however, does not preclude a significant improvement in regional ventricular function, as was seen in our second trial of intracoronary streptokinase despite the prolonged duration of symptoms. Whether this observed improvement in regional wall motion imparts a survival advantage is unknown.

In contradistinction to intracoronary streptokinase, primary PTCA was associated with a significant improvement in global ventricular function. Our findings have subsequently been corroborated by Rothbaum et al. ${ }^{18}$ who demonstrated that patients with anterior myocardial infarction achieved a $13 \pm 12 \%$ increase and patients with inferior myocardial infarction a $10 \pm$ $12 \%$ absolute increase in global EF after primary PTCA. Although primary angioplasty therapy provides high rates of coronary recanalization and effective preservation of global ventricular function, it entails an obligatory time delay of 1 to $1 \frac{1}{2}$ hours from patient presentation to reperfusion, and requires highly sophisticated personnel and resources. Thus, it is unlikely that angioplasty therapy will be widely applied as a primary reperfusion modality. On the other hand, while initial intravenous thrombolytic therapy allows earlier reperfusion than angioplasty alone, it carries a significant risk of cerebral hemorrhage $(0.4$ to
$1.4 \%)^{19}$ or extensive intramural hemorrhage of the infarct artery or the associated myocardial zone. ${ }^{20}$ For these reasons, a randomized clinical trial comparing sequential intravenous thrombolytic therapy and angioplasty to primary angioplasty alone should be conducted in the subset of patients who can be treated within 3 hours of symptom onset.

Our experience with intravenous rt-PA alone has provided conflicting results. The pilot study showed no improvement in regional wall motion in patients treated solely with rt-PA, whereas the subsequent Thrombolysis and Angioplasty in Myocardial Infarction (TAMI) trial showed significant improvement in regional function in patients treated with rt-PA alone (Fig. 7).

Similar conflicting data exist for rt-PA therapy followed by immediate angioplasty. The initial pilot study $^{14}$ suggested that immediate angioplasty was essential for myocardial salvage, since only patients treated with angioplasty had improvement in regional ventricular function. In the TAMI study, ${ }^{21}$ however, equal improvement in regional function occurred whether patients were treated with immediate or deferred PTCA. This may be explained by 2 major differences in trial design between the pilot study and TAMI study: (1) Patients in the pilot study were treated 3.8 hours after symptom onset, whereas those in the TAMI study were treated 2.9 hours after symptom onset; and (2) the pilot study used a short duration of rt-PA infusion and lower mean dose than that used in the TAMI trial. Thus, earlier and more prolonged rt-PA infusion in the TAMI trial may have minimized coronary reocclusion and allowed better preservation of ventricular function without resorting to immediate PTCA.

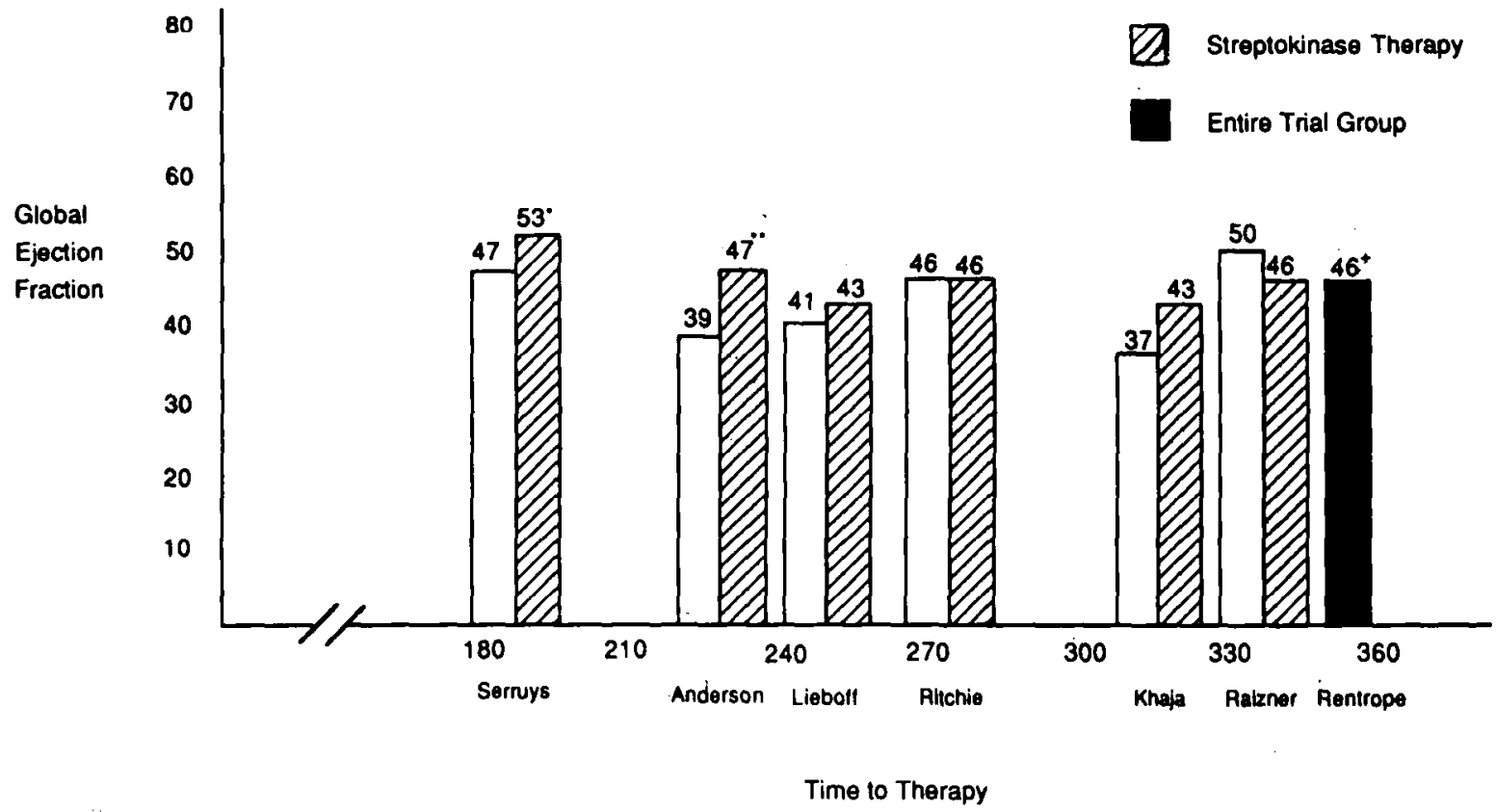

FIGURE 6. The impact of intracoronary streplokinase on ventricular function at the time of discharge is depicted. Patients treated in the Andersen study ${ }^{17}$ and the Serruys study ${ }^{4}$ had an improvement in global ventricular function. In both of these studies patients were treated within 4 hours of symptom onset. $" p=0.0001 ; * p<0.05 ;+=$ Rentrop did not report chronic ejection fraction for treatment groups; no change in ejection fraction occurred in streptokinase or control group. 
We have now had the opportunity to study extensively the changes in ventricular function after intravenous rt-PA in the TAMI study 22 based on the 266 of 386 patients $(69 \%)$ treated $2.9 \pm 1.1$ hours after symptom onset who underwent serial, paired contrast ventriculography of suitable quality for analysis. Linear regression analysis revealed that relief of chest pain before catheterization, baseline EF less than $55 \%$, presence of Thrombolysis in Myocardial Infarction Trial flow grade II or III and lack of coronary reocclusion or use of emergency coronary bypass were independently associated with improved global ventricular function. The findings of the TAMI trial are relevant to our earlier experience with sequential intravenous streptokinase therapy and immediate PTCA as reported by Fung et al. ${ }^{8}$ Although regional wall motion was significantly improved after successful thrombolytic therapy (either intravenous streptokinase or intravenous rt-PA), the major differences between these 2 treatment strategies resided in patients in whom thrombolytic therapy had failed. Because $36 \%$ of the patients in the TAMI study in whom thrombolytic therapy was unsuccessful and reperfusion was achieved by angioplasty had documented coronary reocclusion, the impact of PTCA mediated-reperfusion was negated. On the other hand, patients treated with PTCA in whom streptokinase therapy was unsuccessful had a $9 \%$ point increase in global EF and a significant improvement in regional wall motion. These findings have been corroborated by Stack et al. ${ }^{23}$ Although intravenous streptokinase resulted in only a $40 \%$ reperfusion rate, the addition of angioplasty lead to an increase in a global EF from 44 to $49 \%$ at the time of hospital discharge $(p<0.0001)$ in the Stack study. The beneficial impact of a systemic thrombolytic agent in patients undergoing "salvage" PTCA has been further investigated by Stack et al. ${ }^{24}$ This group examined 58 patients who underwent PTCA after unsuccessful thrombolytic therapy with rtPA compared with 24 patients who underwent PTCA after unsuccessful therapy with rt-PA and urokinase ( 0.5 to 2.0 million units). Coronary reocclusion rates decreased dramatically (from 31 to $5 \%$ ) by the addition of urokinase. More important, no change in global or regional ventricular function was evident among patients treated with rt-PA alone, whereas a $6 \%$ increase in global EF and a $0.36 \mathrm{SD} /$ chord increase in regional wall motion ( $p<0.004)$ occurred among patients treated with both rt-PA and urokinase. These findings suggest that the addition of a systemic thrombolytic drug significantly decreases coronary reocclusion and enhances myocardial salvage when PTCA is performed after unsuccessful intravenous thrombolytic therapy. A compelling argument can thus be made for a formal, prospective, randomized clinical investigation of sequential intravenous thrombolytic therapy with clotselective vs systemic thrombolytic drugs and sequential angioplasty.

As we have matured in our understanding of reperfusion therapy, the critical role that early therapy plays in myocardial salvage has become apparent. Koren et al. ${ }^{25}$ demonstrated that very early administration of thrombolytic therapy results in effective preservation of global ventricular function, since only patients with intravenous streptokinase therapy within 90 minutes of symptom onset had significant increase in EF. Our experience with community hospital administration of rt-PA also suggest good initial ventricular function in patients treated less than 2 hours after symptom onset. These findings provide further impetus for establishing reperfusion protocols for emergency room physicians, and perhaps even paramedics, to administer these agents as soon as possible after myocardial infarction has been diagnosed.

\section{Conclusions}

In 1979, Rentrop et al. ${ }^{26}$ demonstrated that nonsurgical coronary recanalization could be achieved during the evolutionary stages of acute myocardial infarction. Although coronary recanalization could be
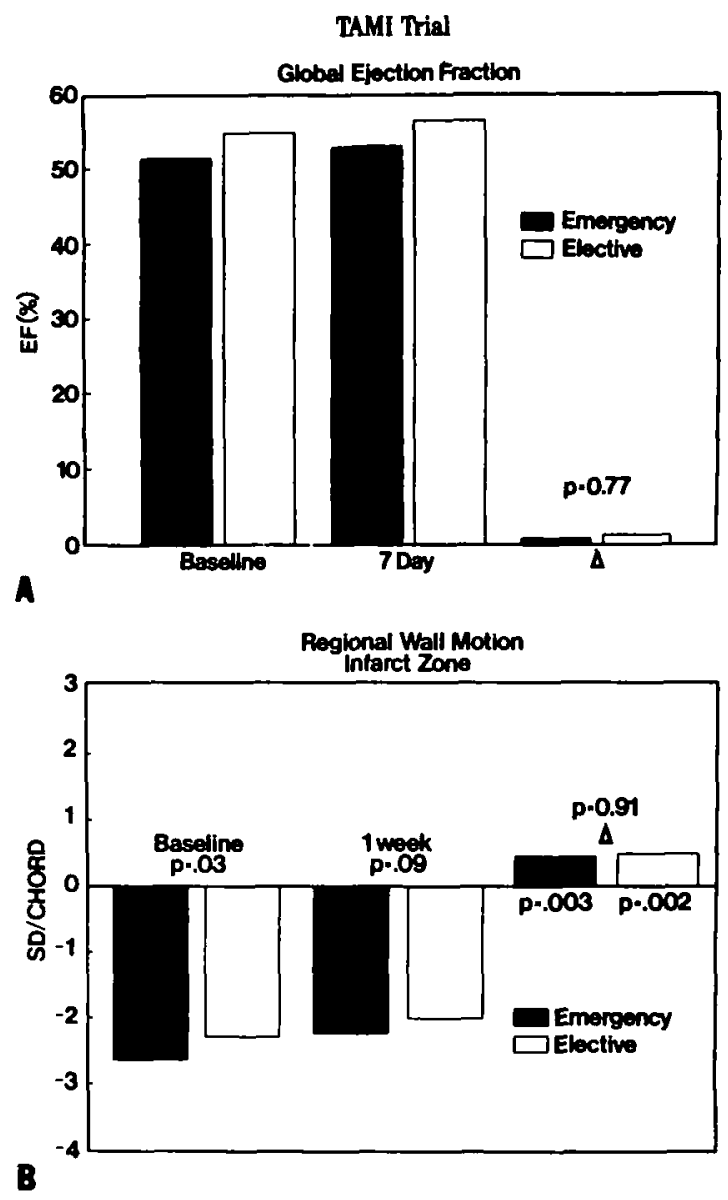

FIGURE 7. Baseline and 7 -day left ventrlcular ejection fraction (EF) in patients treated with emergency or elected percutaneous transluminal coronary angioplasty (PTCA). Regional wall motion of the infarct zone for patients treated with emergency or elected PTCA are demonstrated. No improvement in global ejection fraction occurred whether emergency or elected PTCA was applied. Both groups had significant improvement in regional ventricular function. No difference in the improvement in reglonal wall molion occurred, however, whether emergency or elected PTCA was applled. SD = standard deviation; TAMI = Thrombolysis and Angioplasty in Myocardial Infarction Study Group. 
achieved, the clinical benefit of this therapy remained un proved until the completion of the GISSI ${ }^{i}$ and Netherlands Interuniversity studies, both of which showed evident clinical benefit of thrombolytic reperfusion on survival. Major questions, however, still exist about optimal reperfusion therapy. In assessing the clinical use of these reperfusion strategies, their impact on mortality, coronary recanalization rates and preservation of ventricular function must be compared. Our own experience suggests that intracoronary thrombolytic therapy is outdated. Although primary angioplasty therapy is an effective reperfusion strategy associated with high recanalization rates and effective preservation of ventricular function, logistic constraints of time delay and intense manpower requirements make it applicable to only a small number of cases. Intravenous thrombolytic therapy would be more applicable and is likely to become standard care for acute myocardial infarction. Our experience suggests that further augmentation of ventricular function does not occur with immediate PTCA in patients in whom thrombolytic therapy is successful. Significant clinical benefit can still be derived, however, in patients in whom thrombolytic therapy has been unsuccessful, especially when a systemic thrombolytic agent (streptokinase or urokinase) is added. Because our clinical criteria are currently inadequate to predict recanalization status noninvasively, ${ }^{27}$ our current reperfusion strategy involves very early administration of thrombolytic therapy to suitable patients followed by immediate catheterization to document arterial recanalization. In patients with unsuccessful thrombolytic reperfusion, immediate angioplasty is applied. When this strategy is undertaken then more than $90 \%$ of patients leave the catheterization laboratory with a patent infarct-related artery. Patients in whom thrombolytic reperfusion is unsuccessful still derive significant myocardial salvage from PTCA-mediated reperfusion. The requirement that all patients with acute myocardial infarction who received thrombolytic therapy undergo immediate cardiac catheterization carries adverse logistic and financial consequences. A more effective strategy would be to stratify patients according to risk. Patients with extensive areas of jeopardized myocardium (anterolateral myocardial infarction or cardiogenic shock) are at highest clinical risk, and are most likely to benefit from this aggressive reperfusion strategy. Patients at lower risk could be treated with intravenous thrombolytic therapy alone, delaying catheterization and PTCA of an appropriate subgroup until the most desirable interval after thrombolytic therapy.

Acknowledgment: We wish to thank Brenda White for her expert secretarial assistance in preparation in this manuscript.

\section{References}

1. Gruppo Italiano Per Lo Studio Della Streptuchinasi Nell'Infarcto Miocardico [GISSI). Effectiveness of intruvenous thrombolytic treament in acute myocardial infurction. Lancet $19816 ; 1: 397-40^{\prime}$

2. Simoons ML, Serruys PW, Van Den Brand M, Bar F. DeZwaan C, Res J.
Verheugt FWA. Krauss XH, Remme WJ, Vermeer F, Lubsen I. Improved survival after early thrombolysis in acule myocardial infarction: a randomized trial by the Interuniversity Cordiology Institute in The Netherlonds. Lancet 1985:/1:578-582.

3. Stadius ML. Davis K, Maynard D. Ritchie JL, Kennedy JW. Risk strutificution for 1 year survival bosed on charucteristics identified in the eurly hours of acute myocardial infarction. The Western Washington Intracoronary Streptokinase Trial. Circulation 1986; $7: 703-711$.

4. Serruys PW. Simoons ML, Suryapranata $H$, Vermeer F, Wijns W, Van den Brand M, Bar F, Zwaan C, Krauss XH. Remme WJ. Res I, Verheugl FWA, Van Domburg R. Lubsen J, Hugenholtz PG. Presevation of global and regional left ventricular function after early thrombolysis in acute myocurdial infarction. [ACC 1986:7(4):729-742.

5. Rentrop P, Blanke H, Karsch KR, Kaiser H, Kostering H, Leitz K. Selective intrucoronury thrombolysis in acute myocardial infarction and unstable angina pectoris. Circulation 1981;63(2):307-316.

6. Meyer J, Merx W, Schmitz H. Erbel R, Kiesslich T, Dorr R. Lambertz H, Bethge C. Krebs W. Bardos P. Minale C. Messmer BJ. Effert S. Percutaneous transluminal coronary angioplasty immediutely after intracoronury streptoIysis of transmural myocardial infarction. Circulation 1982:66 (5):905-913.

7. Phillips SI. Kongtahworn C, Zeff RH, Benson M, Iannone L, Brown T, Gordon DF. Emergency coronary artery revascularization: $A$ possible therapy for acute myocardial infarction. Circulation 1979:60:241-246.

B. Fung AY, Lai P, Topol EJ. Bates ER, Bourdillon PDV, Walton JA, Mancini GBI, Kryski T, Pitt B, O'Neill WW. Value of percutaneous transluminol coronary angioplasty after unsuccessful intravenous streptokinase therapy in acute myocurdial infurction. Am I Cardiol 1986;58:686-691.

9. Falsetti HL. Marcus ML. Kerber RE, Skorton D] [editorial]. Quantification of myocardial ischemia and infarction by left ventricular imaging. Circulation 1981;63(4):747-751.

10. Hugenhaltz PG. Acute coronary artery obstruclion in myocardial infarction: Overview of thrombolytic therapy. JACC 1987:9:1375-1384.

11. O'Neill WW, Topol EJ, Fung A, Bourdillon PDV, Nicklas [M, Walton I. Bates ER, Pitt B. Coronary angioplasty as therapy for acute myocardial infarc(ion: University of Michigon experience. Circulation 1987;6(suppl II):11-79-1187.

12. Khaja F, Walton JA, Brymer JF. Lo E, Osterberger L, O'Neill WW, Golfer HT, Weiss R, Lee T, Kurian T, Goldberg D. Pitt B, Goldstein S. Intrucoronary fibrinalytic therapy in acute myocardial infarction: report of a prospective randomized trial. $N$ Engl / Med 1983:308:1305-1311

13. O'Neill WW, Timmis GC. Bourdillon PD, Lai P. Gangadharan V. Walton I. Ramos R. Laufer N. Gordon S. Schork MA. Pill B. A prospective rundomized clinical trial of intracoronary streptokinase versus coronary angioplasty for acule myocardial infarction. $N$ Engl / Med 1986;314:812-818.

14. Topol E]. O'Neill WW. Langburd AB, Walton JA, Bourdillon PDV, Bates ER, Grines CL, Schork MA, Kline E, Pítt B. A randomized, placebo-controlled trial of intravenous recombinant tissue-type plasminogen activator and emergency coronary angioplasty in patients with acute myocurdial infarction. Circulation 1987:75:420-428.

15. Topol El, Morris DC. Smalling RW. Schumacher RR, Taylor CR, Nishikawi A. Liberman HA. Collen D. Tufte ME. Grossbard EB. O'Neill WW A multicenter, randomized. placebo-controlled trial of a new form of intravenous recombinant tissue-type plasminogen activatior (activase) in acute myorardial infarction. IACC 1987;9:1205-1213.

16. Topol EJ. Bates ER. Walton IA. Bauman G. Wolfe S. Maino I. Bover L. Gorman L. Kline E. Pitt B, O'Neill WW. Community hospital administration of intravenous tissue plasminogen activalor in acule myocardial infarction: $1 \mathrm{~m}$ proved timing. thrombolytic efficacy and ventricular function. JAC 1987; 10:1173-1177

17. Anderson |L, Marshall HW. Bray BE, Lutz |R. Froderick PR. Yanowiz FG. Datz FL, Klausner SG. Hagan AD. A randomized triul of intrucoronary streptokinase in the treatment of acute myocardial infarction. $N$ kingl I Med 1983:308(22):1312-1318.

18. Rothbaum DA, Linnemeier TJ. Landin R]. Steinmetz EF, Hillis [S, Hallam CC. Noble RJ. See MR. Fmergency percutaneous Irunsluminal coronary angioplusly in acute myocurdial infarction: a 3 year experience. JACC 1987:264372.

19. Braunwald E. Knatterud GL, Passamani E. Robertson TL. Solomon R. Ipdate from the Thrombolysis in Myocardial Infarction Trial |letter]. IACC 1987;10:970.

20. Waller BF, Rothbaum DA. Pinkerton CA. Cowley M]. Linnemeier T], Orr C, Irons M. Helmulh RA. Wills ER. Aust C. Status of the myocardium and infurct-reluted coronury artery in 19 necropsy patients with acute recanalization using pharmacologic (streptokinase, $r$-t issue plasminogen activator), mechanical |percutaneous Iranslaminal coronury angioplasty' or combined Nepes of reperfusion therapy. IACC 1987:9:785-801.

21. Topol E]. Calirf RM. George BS, Kereiakes DI. Abbottsmith CW. Candela RI. Lee KI. Pilt B. Stack RS, O'Neill WW and the Thrombolysis and Angioplasty in Myocardial lnfarclion (TAMI] Study Group. A randomized trial of immediate versus delayed elective angioplasty after intravenous lissue plasminogen activator in ucute myocardial infaretion. $N$ Engl I Med 1987:317: $581-588$.

22. O'Neill WW. Topol E], George BS, Kerciakes DI, Ahbotsmith CW, Candelit R]. Boswick i. Califf RM. Improvement in left ventricular function ofter 
thrombolytic therapy and angioplasty: Results of the TAMI study (abstr). Circulation 1987;76:suppl IV:IV-259.

23. Stack RS, O'Connor CM, Mark DB. Hinohara T, Phillips HR, Lee MM Ramirez NM. O'Callaghan WG, Simonton CA. Carlson EB, Morris KG, Behar

VS, Kong Y. Peter RH. Califf RM. Coronary perfusion during acute myocardiol infarction with combined coronary angioplasty and high-dose intravenous streptokinase therapy. Circulation, in press.

24. Stack RS, O'Neill WW, Hinohara T, Boswick IM, Topol E, George B, Califf RM. TAMI I versus TAMI II: Does choice of initial thrombolytic therapy influence outcome of salvage angioplasty (abstr)? IACC 1988:11:193A.
25. Koren G, Weiss AT, Hasin Y, Appelbaum D, Welber S, Rozenman Y, Lotan C, Mosseri M, Sapoznikov D, Luria MH, Gotsman MS. Prevention of myocardial damage in acute myocardial ischemia by early treatment with intravenous streptokinase. N Engl I Med 1985;313\{22):1384-1389.

26. Rentrop P, DeVivie ER, Karsch KR, Kreuzer H. Acute coronary occlusion with impending infarction as an angiographic complication relieved by a guide-wire recanalization. Clin Cardiol 1978;1:101-106.

27. Kircher BE, Topol EJ. O'Neill WW, Pitt B. Prediction of ocute myocardial infarct coronary artery recanolization after intravenous thrombolytic therapy. Am I Cardiol 1987:59:513-515. 